\title{
Individual variation in sleeping metabolic rates in infants
}

\author{
David Hull, Alastair J McArthur, Katherine Pritchard, Dilys Oldham
}

\begin{abstract}
Aim-To measure the variation in sleeping metabolic rate (SMR) of healthy infants in the first year of life.

Methods-Attempts were made to measure SMR in the home of one group of infants at monthly intervals over the first year of life and of another group in the 1 to 12 age range, over three consecutive days. Sixty one infants were recruited and 181 measurements made. In 11 infants six or more satisfactory measurements were made a monthly intervals and in another 11 infants, three consecutive daily measurements were obtained. Parents chose the clothing and bedding that they judged their infant needed to fall asleep. The room air and radiative temperatures, humidity, and amount of insulation were recorded.

Results-The mean (SD) SMR was 2.4 (0.4) watts $(\mathrm{W}) / \mathrm{kg}$ or $45(10) \mathrm{W} / \mathrm{m}^{2}$. The rate was the same for infants in the age groups $0.25,0.5,0.75$, and 1 years; individual infants did not show a systematic change with age. There was wide variation. Ninety eight per cent of infants had a SMR between 1.8 and $3.1 \mathrm{~W} / \mathrm{kg}$. The mean SMR for the infants measured on three consecutive days varied from 1.7 to 3.1 W/kg, and SMR varied within infants, from 0.06 to $0.86 \mathrm{~W} / \mathrm{kg}$. The variation within six to 11 measurements on infants over the first year of life ranged from 0.38 to $1.05 \mathrm{~W} / \mathrm{kg}$.

Conclusion-Infants in the first year of life exhibit wide variations in SMR from day to day and from month to month. As the range is wide, guidance on clothing and bedding for thermal comfort can be given only in broad terms.

(Arch Dis Child 1996;75:288-291)
\end{abstract}

Department of Child Health, University Hospital, Queen's

Medical Centre,

Nottingham NG7 2UH

D Hull

K Pritchard

D Oldham

Department of
Physiology and
Environmental
Science, University of
Nottingham, Sutton
Bonington Campus,
Loughborough
AJ McArthur
Correspondence to:
Professor Sir David Hull.

Accepted 19 June 1996
Keywords: sleeping metabolic rate, thermal environment.

In a previous study we found that the sleeping metabolic rate (SMR) of infants aged 1 to 12 months, measured in a specially designed nursery, rose during the first months of life, and that there were large differences in SMR between infants of the same age throughout the year. ${ }^{1}$ These differences did not appear to be related to the time of the last feed, gender, or time of day. At a given age, the range in SMR was so wide that the clothing and room temperature at which the average infant might settle would be uncomfortably warm for some or cool for others.
The aim of the present study was to investigate the extent to which these differences in SMR occurred as a consequence of variations in metabolism within one infant, or were due to consistent differences between individuals.

\section{Methods}

SUBJECTS

Normal healthy infants were recruited from the local community by placing posters in 30 general practitioners' surgeries and health clinics in the Nottingham area. In addition, baby clinics were visited on a regular basis in order to enlist parents.

The aim was to study one group of infants at monthly intervals over the first year of life, starting as soon as possible after birth, and another group daily on three consecutive days. The programme was often frustrated because the infants did not settle to sleep. In 11 infants it was possible to measure SMR on six or more occasions at monthly interval in the first year. These infants were labelled 1 to 11 ; there were six boys and five girls. A total of 90 measurements were made on these 11 infants. The largest number of observations (monthly) on an individual infant during the year was 11, and the average period between measurements was 0.11 years (minimum $=0.05$, maximum $=$ $0.34)$. Successful measurements on three consecutive days were made on 11 infants; there were four boys seven girls labelled A to $K$. It was our intention to measure SMR at the same time each day, but a short delay often occurred due to a lack of cooperation from the subjects! This delay varied between nine and 125 minutes but the longest delay (during the three days) was usually less than 20 minutes. In 39 infants the series was incomplete. In total, we made 188 measurements of sleeping metabolic rate on 61 infants between November 1991 and March 1994.

\section{EXPERIMENTAL PROCEDURE}

The SMR was measured on the infants in their homes by indirect (open circuit) calorimetry using the Datex Deltatrac Metabolic Monitor. ${ }^{2}$ The Deltatrac measures the metabolic rate at one minute intervals and automatically calculates the mean and SD of these readings over a given time interval. In all instances the parents dressed and covered the infant in the amount of insulation that they felt was appropriate. The air temperature in the home was not adjusted, and the infants were placed in the usual location and position for their daytime sleep.

A ventilated hood was placed over the head of the sleeping infant about 10 minutes after 


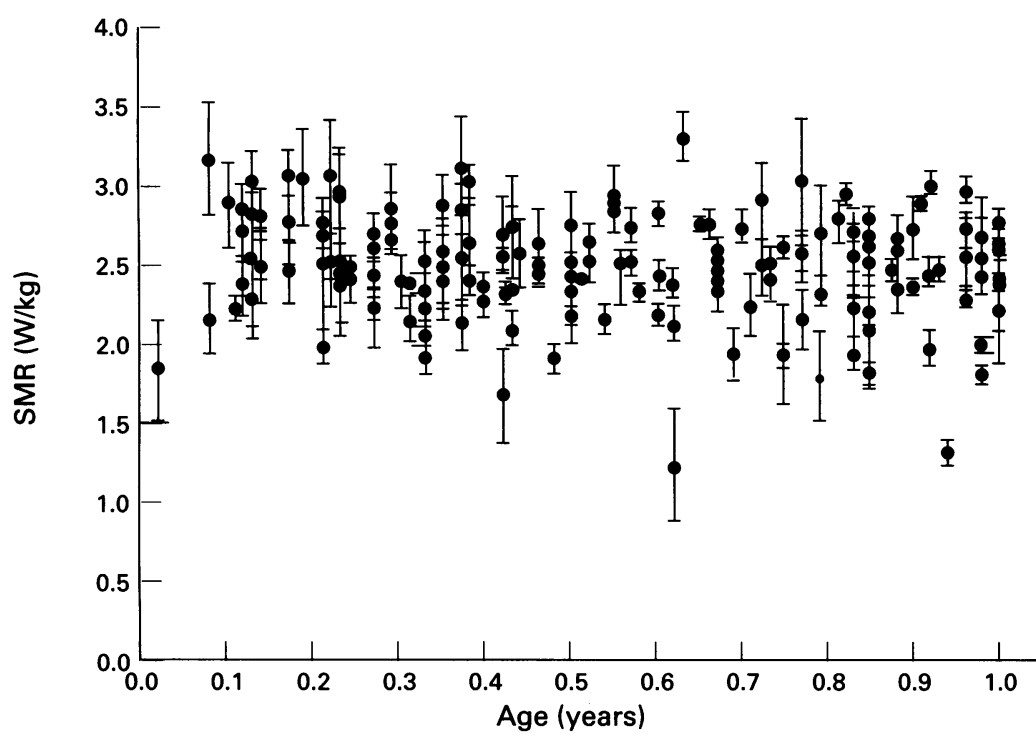

Figure 1 SMR compared with age for infants at home. The data include all the measurements for infants studied on consecutive days and at monthly intervals. The vertical bars indicate the $S D$ of the mean of measurements made at minute intervals over 15 minutes.
Table 1 Mean (SD) values of SMR (W/kg) for infants in four age groups. Measurements were made in a nursery or at home, as indicated

\begin{tabular}{|c|c|c|c|c|}
\hline \multirow{2}{*}{$\begin{array}{l}\text { Age } \\
\text { (years) }\end{array}$} & \multicolumn{2}{|c|}{ Nursery } & \multicolumn{2}{|l|}{ Home } \\
\hline & $\begin{array}{l}\text { No in } \\
\text { group }\end{array}$ & $\begin{array}{l}S M R \\
\text { (W/kg) }\end{array}$ & $\begin{array}{l}\text { No in } \\
\text { group }\end{array}$ & $\begin{array}{l}S M R \\
(W / k g)\end{array}$ \\
\hline 0.25 & 8 & $2.0(0.42)$ & 8 & $2.4(0.10)$ \\
\hline 0.50 & 11 & $2.6(0.24)$ & 9 & $2.4(0.26)$ \\
\hline 0.75 & 12 & $2.6(0.40)$ & 9 & $2.4(0.36)$ \\
\hline 1.00 & 8 & $2.3(0.44)$ & 10 & $2.5(0.17)$ \\
\hline
\end{tabular}

The difference between the nursery and home measurements at 0.25 years was significant $(p<0.05)$.

significantly lower than the mean value of 2.4 $\mathrm{W} / \mathrm{kg}$ at home $(t$ value $=-2.82, \mathrm{p}<0.05)$. There was no significant difference between the corresponding mean values of air temperature, amount of clothing and bedding insulation, body mass, time since last feed, axilla temperature, or duration of sleep before the measurements in the nursery and at home. The mean value of SMR measured at home for the youngest age group ( 0.25 years) is not significantly different from the mean values (nursery and home) for the other three age groups.

Figure 2 shows the air and mean radiative temperatures that surrounded infants asleep in the home (monthly observations). The air temperature was, on average, $0.5^{\circ} \mathrm{C}$ above $T_{r}$ (the temperature difference $T_{a}-T_{r}$ ranged from -1.8 to $5.8^{\circ} \mathrm{C}$ ), and was within $1^{\circ} \mathrm{C}$ of $\mathrm{T}_{\mathrm{r}}$ on about half of the occasions. The vapour pressure was between 0.9 and $2.0 \mathrm{kPa}$ (mean $(S D)=1.3(0.3) \mathrm{kPa})$. Figure 3 shows the clothing and bedding insulation, which ranged from 0.8 to 7 togs (100 to $900 \mathrm{~s} / \mathrm{m})$. Most parents provided between 1 and 3 togs of insulation for their infant. There is a weak negative correlation between insulation and $T_{a}$ $(r=0.31)$.

Figure 4 illustrates the time course of SMR during the first year of life for two infants (2 and 6). SMRs did not vary significantly with age during the period of study; the SMR for infant 2 was consistently higher than that of infant 6 . Figure 5 presents the monthly values of SMR for all 11 infants during their first year of life. The difference between the highest and lowest value of SMR for each infant ranged from $0.38 \mathrm{~W} / \mathrm{kg}$ (infant 2) to $1.05 \mathrm{~W} / \mathrm{kg}$ (infant 11). There was no systematic change in SMR with age for any of the infants. While the mean value of the SMRs over the first year of life differed between infants, the size and significance of this variance could not be calculated because measurements at each month on each infant was not obtained.

Table 2 shows the air temperature, amount of clothing and bedding insulation, and axilla temperature for each infant studied on consecutive days. The air temperature was at a similar value on the three days, the largest difference between days was $3.5^{\circ} \mathrm{C}$ in infant $\mathrm{A}$. The mean radiative temperature, measured on 21 of the 33 occasions, was on average $0.3^{\circ} \mathrm{C}$ below $T_{a}$. The largest temperature difference $T_{a}-T_{r}$ was $1.8^{\circ} \mathrm{C}$. The vapour pressure varied between 1.1 and $2.0 \mathrm{kPa}$ (mean (SD) = $1.4(0.2) \mathrm{kPa}$ ). The insulation provided by the 0.75 , and 1.00 years ( \pm 0.02 years). For the 0.25 year age group, the mean value of SMR determined in the nursery $(2.0 \mathrm{~W} / \mathrm{kg})$ is 


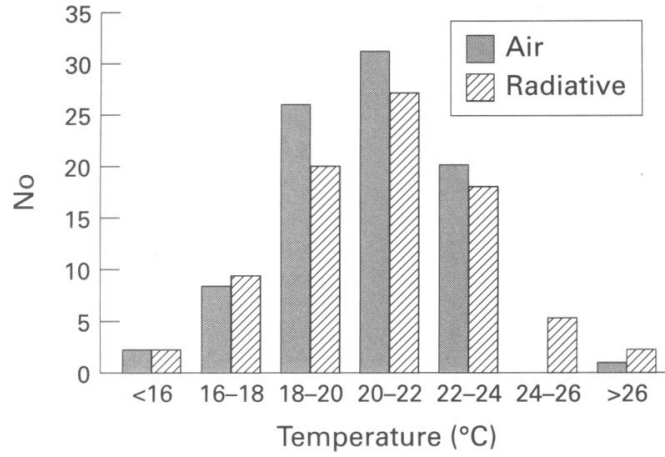

Figure 2 Air and mean radiative temperatures of the environment surrounding infants asleep at home (from monthly observations).

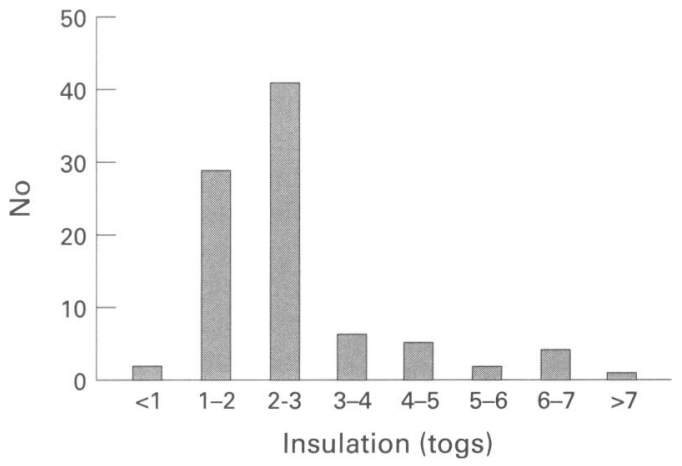

Figure 3 Tog value of the insulation selected by parents when their infants were asleep at home (from monthly observations).

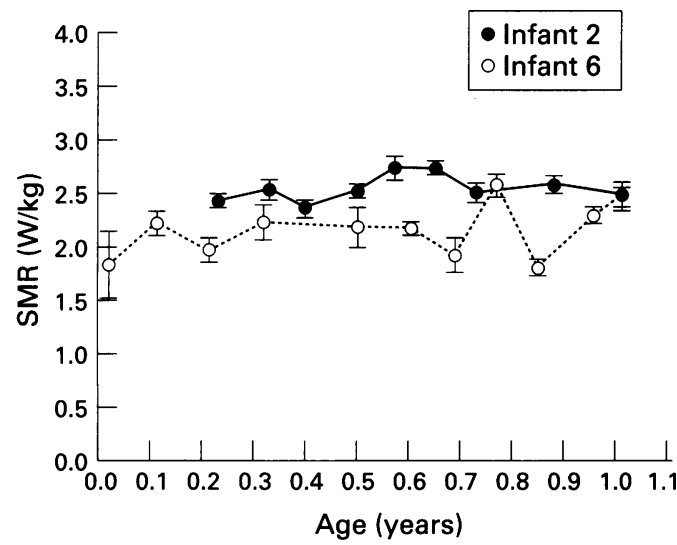

Figure 4 SMR of infants 2 and 6 compared with age during the first year of life. The vertical bars indicate the $S D$ of the mean of measurements made at minute intervals over 15 minutes.

clothing and bedding ranged from 1.7 togs (infant B) to 6.6 togs (infant $\mathrm{K}$ ), but the insulation for each infant did not alter much over the three days. The largest difference in insulation between days was 4.6 togs for infant $\mathrm{K}$ who was in a room at about $16.5^{\circ} \mathrm{C}$. However, the largest day to day difference in insulation was less than 0.7 togs for seven of the 11 infants, and less than 1.5 togs for all except infant $K$. Table 2 also shows that the difference between the highest and lowest value of $T_{a x}$ for an individual over the three days was between 0.1 and $1.0^{\circ} \mathrm{C}$ (mean difference $=0.4^{\circ} \mathrm{C}$ ).

The time since the last feed was between 10 and 180 minutes. Infants $A$ to $E$ and infant $K$ had been fasted for more than one hour on all three days, whereas infants $\mathrm{F}$ to $\mathrm{H}$ had been fed

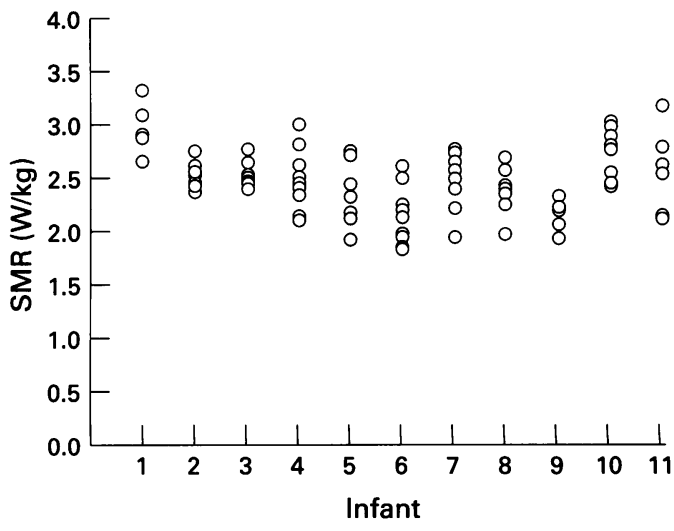

Figure 5 Monthly values of SMR for 11 infants.

during the hour previous to measurement on all three days. Infant I had been fasted for more than two hours on days 1 and 2 , and less than one hour on day 3. Infant J had been fasted for less than one hour on days 1 and 2 , and for more than two hours on day 3.

Figure 6 shows the mean (SD) values of SMR on the three consecutive days for infants $A$ to $K$ plotted against age. The mean values of SMR were between 1.7 and $3.1 \mathrm{~W} / \mathrm{kg}$. For individuals, the difference between the highest and lowest SMR during the three days ranged from 0.06 $\mathrm{W} / \mathrm{kg}$ (infant $\mathrm{A}$ ) to $0.86 \mathrm{~W} / \mathrm{kg}$ (infant $\mathrm{E}$ ).

There was a large variation in SMR for infant E. She had fasted for 60,80 , and 70 minutes on days 1,2 , and 3 , respectively, and had been asleep for about 10 minutes before each set of measurements commenced. Table 2 shows that $\mathrm{T}_{\mathrm{a}}$ was $2.5^{\circ} \mathrm{C}$ cooler on day 3 than day 1 . However, she had an 'extra' 0.5 togs of insulation on day 3 to compensate for the lower $\mathrm{T}_{\mathrm{a}}$. She lay in the same position (supine) on all three days.

\section{Discussion}

Over 50 years ago, Clagett and Hathaway measured the SMR of eight infants on four to seven occasions during the first year of life. ${ }^{3}$ The difference between the highest and lowest values of SMR they recorded for each infant ranged from 0.19 to $0.63 \mathrm{~W} / \mathrm{kg}$, which is similar to the difference we found with ranges from 0.38 to $1.05 \mathrm{~W} / \mathrm{kg}$ in the monthly studies (fig 5 ), and from 0.06 to $0.86 \mathrm{~W} / \mathrm{kg}$ over three consecutive days (fig 6 ). These values suggest that a large part of the differences in SMR between infants is due to metabolic fluctuations within individuals. Clagett and Hathaway also found that some infants had a consistently higher SMR than others. ${ }^{3}$ So did we, our measurements of SMR at intervals throughout the first year of life indicated that some infants did have a consistently higher metabolic rate during sleep than others. It is difficult to calculate the size of this difference in infants of different size and age.

For the measurements made on three consecutive days, the highest value of SMR for individuals was, on average, $22 \%$ above the lowest value (range from $2-51 \%$ ). For comparison, Karlberg in 1952 measured the rate of oxygen consumption of infants (age 0.02 to 0.50 years) twice, at intervals ranging from 1 to 
Table 2 Air temperature, insulation, and axilla temperature for infants of different ages over the first year of life, measured in the home on three consecutive days

\begin{tabular}{|c|c|c|c|c|c|c|c|c|c|c|}
\hline \multirow{2}{*}{ Infant } & \multirow{2}{*}{$\begin{array}{l}\text { Age } \\
\text { (years) }\end{array}$} & \multicolumn{3}{|c|}{$T_{a}\left({ }^{\circ} C\right)$} & \multicolumn{3}{|c|}{ Insulation (togs) } & \multicolumn{3}{|c|}{$T_{a x}\left({ }^{\circ} \mathrm{C}\right)$} \\
\hline & & Day 1 & Day 2 & Day 3 & Day 1 & Day 2 & Day 3 & Day 1 & Day 2 & Day 3 \\
\hline $\mathbf{A}$ & 0.67 & 20.5 & 21.0 & 24.0 & 4.0 & 3.5 & 3.4 & 36.0 & 35.8 & 36.5 \\
\hline B & 0.96 & 20.5 & 21.0 & 22.5 & 1.9 & 1.7 & 2.0 & 36.4 & 36.8 & 36.7 \\
\hline C & 0.98 & 23.0 & 21.5 & 21.0 & 2.0 & 1.9 & 1.8 & 36.0 & 36.7 & 37.0 \\
\hline D & 0.83 & 23.5 & 22.0 & 22.5 & 4.8 & 4.8 & 4.8 & 36.8 & 36.6 & 36.7 \\
\hline E & 0.42 & 21.5 & 20.5 & 19.0 & 2.0 & 1.9 & 2.5 & 36.6 & 36.8 & 36.9 \\
\hline $\mathbf{F}$ & 0.33 & 17.0 & 17.0 & 17.5 & 5.2 & 6.2 & 6.6 & 36.2 & 36.6 & 36.4 \\
\hline G & 0.79 & 23.0 & 21.0 & 20.0 & 3.2 & 2.1 & 2.7 & 36.6 & 36.5 & 36.6 \\
\hline $\mathbf{H}$ & 0.37 & 20.5 & 20.0 & 20.0 & 4.8 & 3.3 & 3.7 & 36.2 & 36.7 & 36.5 \\
\hline I & 0.27 & 22.0 & 22.5 & 22.0 & 2.2 & 2.2 & 2.2 & $\mathbf{n} / \mathbf{m}$ & 36.4 & 36.5 \\
\hline $\mathrm{J}$ & 0.55 & 20.0 & 19.5 & 20.0 & 2.7 & 2.7 & 3.0 & 36.4 & 36.7 & 36.8 \\
\hline $\mathrm{K}$ & 0.23 & 16.0 & 16.5 & 17.0 & 6.6 & 5.0 & 2.0 & 36.3 & 36.5 & 36.4 \\
\hline
\end{tabular}

$\mathrm{n} / \mathrm{m}=$ Not measured.

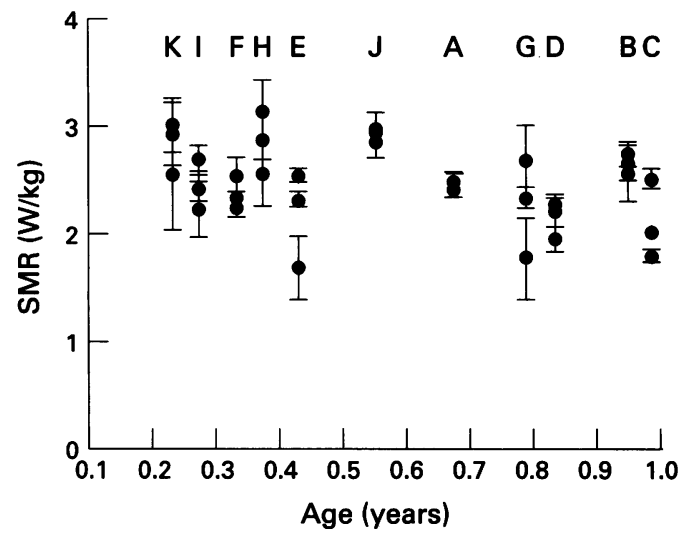

Figure 6 SMR for 11 infants on three consecutive days. The vertical bars indicate the $S D$ of the mean of measurements made at minute intervals over 15 minutes.

10 days. ${ }^{4} \mathrm{He}$ split the infants into three groups: group A consisted of 22 pairs of measurements in which the experimental conditions remained unchanged; in group B (five pairs of measurements) the observations were made at different time intervals following feeding; and in group C (10 pairs of measurements) the observations were made at different times of day. The higher value of oxygen consumption was on average 4 , 8 , and $9 \%$ above the lower value for groups $A$, $B$, and $C$, respectively. The corresponding largest differences in oxygen consumption for individual infants were 8,14 and $23 \%$. We found a wider variation over three days. This is in part because we report the difference between the highest and lowest values of three rather than two measurements of SMR. When the observations made on the first two days only are considered the higher value of SMR is on average $11 \%$ above the lower value (range from $0-44 \%$ ), much closer to Karlberg's finding. Secondly, a sedative was used in 69 of the 74 (34 of 37 pairs) measurements that Karlberg made. It is, therefore, probable that the infants' sleep would have been more uniform between days than the infants in the present study who were in a 'natural' sleep.

We have measured SMR on 288 occasions in infants aged 1 month to 1 year. Taken together, the values follow a Gaussian distribution with a mean (SD) value of $2.4(0.4) \mathrm{W} / \mathrm{kg}$. However, the measurements were made on infants of different age and size, and more than one measurement was made on individual infants. When the metabolic rate is expressed in watts per unit surface area, and limited to single observation per infant, the mean value is 45 (10) $\mathrm{W} / \mathrm{m}^{2}$. The SMR of newborn infants is around $24 \mathrm{~W} / \mathrm{m}^{2}$ on the day of birth, rising to $34 \mathrm{~W} / \mathrm{m}^{2}$ by the end of the first week. ${ }^{56}$ The rise must continue over the subsequent few weeks. Our study in the nursery ${ }^{1}$ suggested that the metabolic rate $\left(\mathrm{W} / \mathrm{m}^{2}\right)$ increases over the first three months, as Azaz et al found. ${ }^{7}$ However, our data on all the infants investigated at home do not reveal an increase in metabolic rate $\left(\mathrm{W} / \mathrm{m}^{2}\right)$ with age. Presumably, metabolism in infants increases at different rates over the first weeks, rather than months, of life.

In conclusion, we report that an infant's rate of heat production during sleep varies significantly from day to day, and from month to month. Consequently, infants should be nursed in environments that allow them to maintain their thermal balance by, for example, adjusting rates of heat loss by postural movements. The flexibility to increase the rate of heat loss is particularly important when a child develops a fever.

It is common teaching that infants and children have higher rates of heat production per unit surface area than adults. Our studies do not support this conclusion. The SMR of infants varies between 30 and $50 \mathrm{~W} / \mathrm{m}^{2}$, which is just below the rate reported for adults at rest. Consequently, an infant with a high metabolic rate is likely to enjoy thermal comfort in similar circumstances to an adult, whereas an infant with a low metabolic rate would require extra insulation. These findings support the general advice given in the government report Back to Sleep. To be more specific about their insulative requirements during sleep would not be helpful.

1 Hull D, McArthur AJ, Pritchard K, Goodall M. Metabolic rate of sleeping infants. Arch Dis Child 1996;75:282-7.

2 Merläinen PT. Metabolic monitor. Int $f$ Clin Monit Comput 1987;4:167-77.

3 Clagett DD, Hathaway ML. Basal metabolism of normal infants from three to fifteen months of age. $\mathrm{Am} \mathfrak{\mathcal { F }} \mathrm{Dis}$ Child 1941;62:967-80.

4 Karlberg P. Determinations of standard energy metabolism(basal metabolism) in normal infants. Acta Paediatr Scand 1952;41:151.

5 Hill JR, Rahimtulla KA. Heat balance and the metabolic rate of newborn babies in relation to environmental temperature; and the effect of age and of weight on basal metabolic rate. F Physiol (Lond) 1965;180:239-65.

6 Hey EN. The relationship between environmental temperature and oxygen consumption in the newborn baby. $\mathcal{f}$ Physiol (Lond) 1969;200:589-603.

7 Azaz Y, Fleming PJ, Levine M, McCabe R, Stewart A, Johnson $P$. The relationship between environmental temperature, metabolic rate, sleep state and evaporative water loss in infants from birth to three months. Pediatr Res 1992;32: 417-23. 